\title{
Breast Cancer Epidemiology, Screening, Treatment and Awareness in Pakistan
}

\author{
*Shamaraz Firdous \\ Associate Professor and Principal Scientist, Pakistan Atomic Energy Commission (PAEC), Islamabad, Pakistan
}

Submission: October 20, 2017; Published: November 02, 2017

"Correspondence Address: Shamaraz Firdous, Associate professor, National Institute of lasers and Optronics (NILOP), Principal Scientist, Atomic Energy Cancer Hospitals, Islamabad, Pakistan, Email: shamaraz@gmail.com

\begin{abstract}
Breast cancer is the most common type of cancer and the most common cause of cancer-related mortality among women worldwide. Pakistan alone has the highest rate of Breast Cancer than any other Asian country as approximately $40 \%$ female patients are with Breast cancer appears at Atomic energy Cancer hospitals (AECHs) during the year 2015-2016. According to a research conducted approximately 1 out of every 10 women are likely to suffer from this disease at any point in their lives and about $80 \%$ of invasive breast cancer occurred in women above 45 years, In this study epidemiology, screening, treatment facilities and awareness of breast cancer by Atomic energy Cancer hospitals among Pakistani will be highlighted. The data is collected by $18 \mathrm{AECHs} \mathrm{running} \mathrm{all} \mathrm{over} \mathrm{country} \mathrm{by} \mathrm{Pakistan} \mathrm{Atomic} \mathrm{Energy}$ Commission (PAEC) through Nuclear Medicine and Oncology Division, Directorate of Medical Sciences, Islamabad.
\end{abstract}

The most prevalent, frequently diagnosed and top most cause of cancer death in female population of Pakistan is breast cancer. The global variation in the incidence and prevalence rates of breast cancer is due to the differences in risk factors and availability of early detection, that lack of breast feeding, diet, less parity and smoking are most significantly associated with breast cancer in patients. Healthcare AECHs not only play an important role in treating patients but are also improving patient screening, as yearly mammography and clinical breast exam is the single most important step that clinicians can take to reduce suffering and death from breast cancer.

Keywords: PAEC: Pakistan Atomic Energy Commission; AECHs: Atomic Energy Cancer Hospitals

Abbreviations: Breast cancer; AECHs Pakistan; Risk factors; Diagnostic and Treatment Facilities; Awareness

\section{Introduction}

Breast cancer represents a significant health problem because of the number of individuals affected by this disease. Thirty per cent of all cancers in women occur in the breast, making it the most commonly diagnosed female cancer. Breast cancer is among the top 20 causes of deaths in Pakistan. Various phenomena serve as protective as well as risk factors for breast cancer. Several characteristics proving to be risk factors include age, weight, family history, physical activity, smoking, hormonal and reproductive factors. Women with advanced age, having middle class family background, higher body mass index and a high ratio of incomplete pregnancies are at significantly increased risk of breast cancer [1-10].

During the year 2015-16 about five thousand women patients with breast cancer diagnoses and treated at AECHs. PAEC Hospitals caters $85 \%$ of the total cancer patient burden of Pakistan. There is a trend of approx, 8-10\% increase in patient turnout each year. The hallmark of all PAEC Cancer Hospitals as shown in Figure 1 is, not only being equipped with most modern equipment, but also operated by skilled teams of doctors, engineers, scientists, physicists and paramedical staff. Highly specialized trainings are required to handle radiation and to use it on the human being. PAEC provide such trainings itself and from abroad to the doctors, scientists and the technical staff. Currently there are 2,494 personnel working in these hospitals including 224 doctors. Atomic Energy Cancer Hospitals are providing teaching and training facilities to postgraduate doctors in the fields of nuclear medicine, radiotherapy radiology, and medical oncology and to scientists in the field of medical physics in collaboration with Pakistan Institute of Engineering and Applied Sciences (PIEAS) Islamabad to strengthen specialized human resource for treatment of cancer.

Nuclear Medicine and Oncology Centers of PAEC are providing state-of-the-art health services to large number of patients across the country. Major services provided at PAEC Cancer hospitals are Diagnostic and Therapeutic Nuclear Medicine, Hormonal Assays, Radiotherapy, Chemotherapy, Indoor Cancer Ward, Breast Care Clinics, Biochemistry, Ultrasonography, Color Doppler, Diagnostic Radiology, Histopathology, Hematology, Molecular Based Diagnostics and Cancer Prevention \& awareness Programs Radiation Oncology started in Pakistan from 1960s, the Pakistan Atomic Energy Commission (PAEC) has established 


\section{Cancer Therapy \& Oncology International Journal}

a number of hospitals all over the country that provide cancer treatment. Initially, these focused primarily on the provision of radiation-treatment facilities. Gradually, they have come to deliver chemotherapy in addition to radiation treatment, but do not have surgery or palliative care services. In common with many developing countries, Cancer hospitals tend to be under equipped and have more patients than is ideal for the facilities available. All PAEC cancer hospitals provide high quality care.

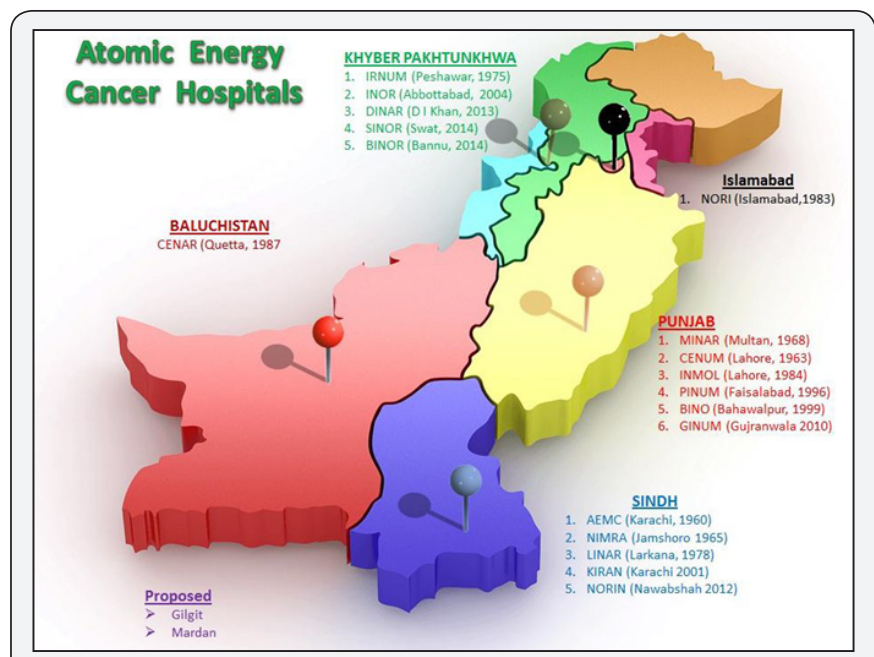

Figure 1: Map of Pakistan Atomic Energy Cancer Hospitals.

The problem is due to appearance of the majority of patients to a cancer treatment centre in the late stages of the disease when cure is usually unlikely. About 5-10 percent of women with breast cancer visit hospitals at an early stage when treatment is usually successful as shown in Figures 2-4. Prevention and screening are not strategies commonly used in Pakistan. Access to cancer treatment suffers from weaknesses of health policy, public awerenence, insufficient financing, as well as inadequate human resources and facilities have resulted in a concentration of services in urban areas. Many people must borrow money to access treatment. A large, unknown number of people in rural areas cannot get treatment at all. Cancer drugs are often very highly priced and out of the reach of poor's people.

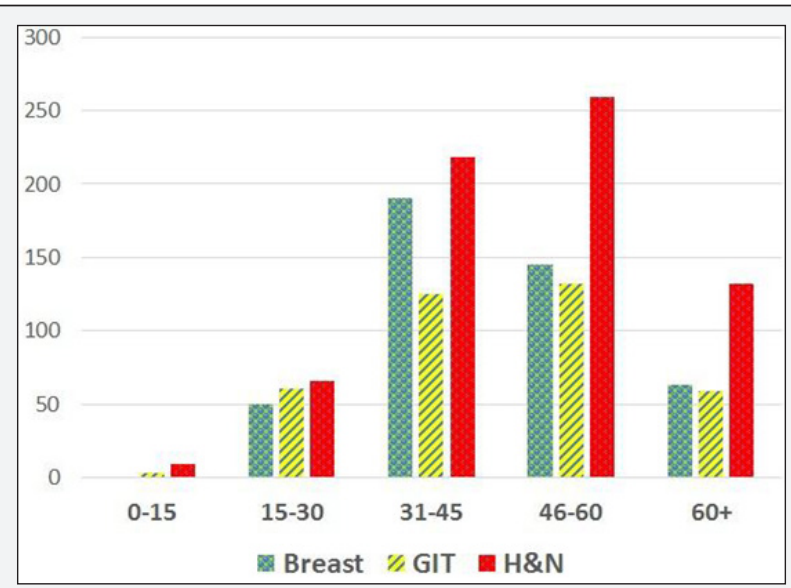

Figure 2: Breast cancer screening age wise at Atomic Energy Cancer Hospitals, 2017.

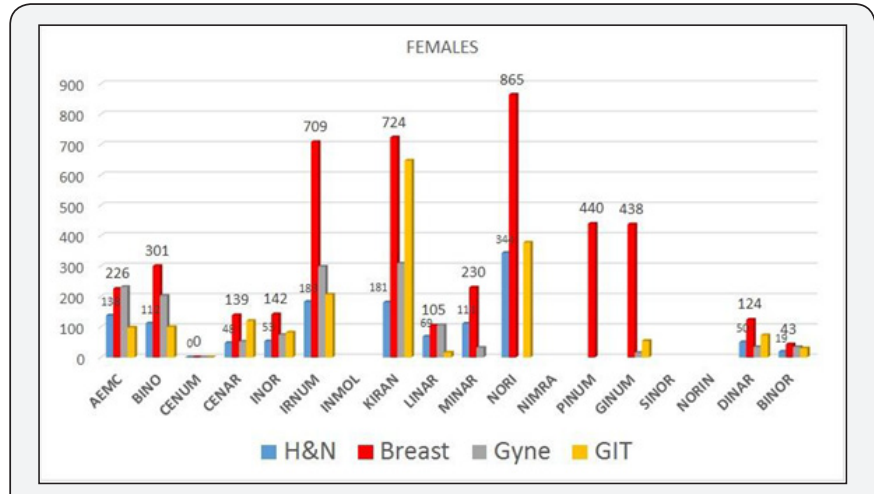

Figure 3 : Breast cancer patients screening and treatment data of 18 Atomic Energy Cancer Hospitals in 4 provinces of Pakistan, 2017.

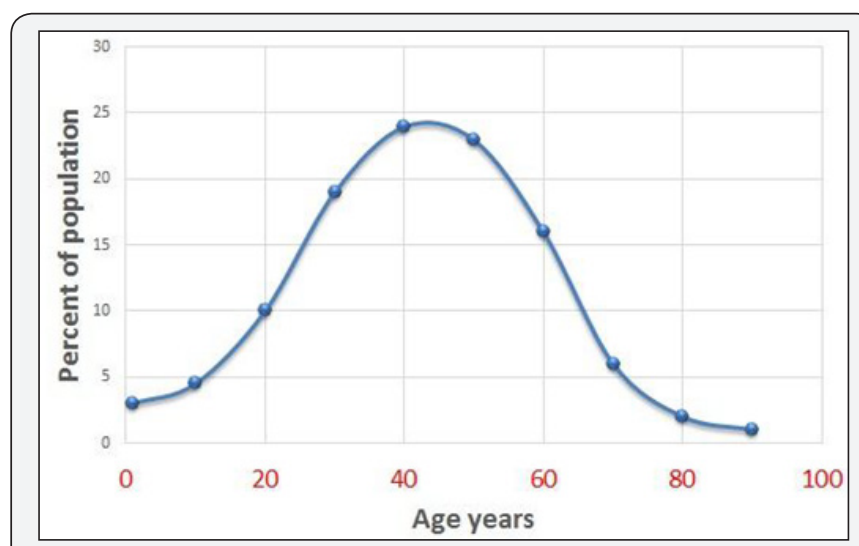

Figure 4 : Breast cancer screening age wise at Atomic Energy Cancer Hospitals, 2017.

Atomic Energy cancer hospitals also launched mobile breast care clinics, comprise of mammography, 3D ultrasound machine and stereo-tactic biopsy, are provided to NIMRA Jamshoro, INMOL Lahore and BINO Bahawalpur. Community outreach is part of cancer prevention \& early detection mission; these centers reach medically less privileged women in approximately $95 \%$ of their examinations. This program allows these institutions to provide life- saving early breast cancer detection services to women all over peripheral areas. The centers with the help of Cancer Patients Welfare Societies and international organizations arrange weekly or fortnightly visits of adjoining remote areas to provide free of cost screening as well as creating awareness among general public about importance of early detection and cancer treatment facilities available at these centers.

In order to provide welfare support to the poorest patients at PAEC hospitals. Cancer Patients Welfare Societies have been registered with social welfare departments. These societies have been working at all hospitals in collaboration with hospital managements to help poor and needy cancer patients. The primary objective of these societies is to mobilize the general public to grant donations for the welfare of cancer patients. In addition, the societies aimed to create awareness in general public about cancer through seminars, symposia and visual 


\section{Cancer Therapy \& Oncology International Journal}

displays (banners, pamphlets and billboards). Pakistan Atomic Energy Cancer Hospitals are highly committed for disseminating information to general public regarding awareness about cancer that it is curable if diagnosed at an early stage. In this regard a number of events like seminars, symposia, conferences, workshops etc are being organized by these centers in collaboration with Cancer Patients Welfare Societies and other medical colleges, universities, hospitals and NGOs for cancer awareness.

\section{Conclusion}

Breast cancer is a common malignancy among women all over the world, especially Pakistan. It may be influenced by the presence or absence of many factors known as risk factors, but these are not the ultimate tool to report the risk of breast cancer. However, they may predict the chances to develop the breast cancer to some extent. The most common and major risk factors include avoiding mother feeding, age, family history, socio-economic status, age at menarche, hormonal therapy after menstruation and physical activity. Alcohol consumption, nightshift working, smoking and use of medicines are also described as risk factors. We described that the facilities provided at our hospitals are well aware of the risk factors, signs and screening modalities for breast cancer. Mobile laboratories, chemotherapy and radiation therapy is the key to success in treatment of breast cancer.

\section{Acknowledgement}

The author acknowledges to the help of Pakistan atomic energy Commission officials, staff and administrators to provide the data through the directorate of Medical Sciences, Islamabad.

\section{References}

1. World Health Organization: Cancer (2009) WHO, Geneva, Switzerland.

2. Murray CJL, Lopez AD (1996) The global burden of disease: a comprehensive assessment of mortality and disability from diseases, injuries, and risk factors in 1990 and projected to 2020. Mass Harvard University Press, Cambridge, USA, p. 27.

3. Wilson CM, Tobin S, Young RC (2004) The exploding worldwide cancer burden: the impact of cancer on women. Int J Gynecol Cancer 14(1): $1-11$.

4. Pillay AL (2002) Rural and urban South African women's awareness of the cancers of the breast and cervix. Ethn Health 7(2): 103-114.

5. Sen U, Sankaranarayanan R, Mandal S, Ramanakumar AV, Parkin DM, et al. (2002) Cancer patterns in eastern India: the first report of the Kolkata cancer registry. Int J Cancer 100(1): 86-91.

6. Bhurghri Y, Bhurhri A, Hassan SH, Zaidi SHM, Rahim A, et al. (2000) Cancer incidence in Karachi, Pakistan: first results from Karachi Cancer Registry. Int J Cancer 85: 325-329.

7. Malik IA, Khan WA, Khan ZK (1998) Pattern of malignant tumors observed in a university hospital: a retrospective analysis. J Pak Med Assoc 48: 120-122.

8. Firdous S, Cancer diagnostic and treatment facilities at AECHs (2017) Medical Review 3: 6-8.

9. Coughlin SS, Uhler RJ, Richards T, Wilson KM (2003) Breast and cervical cancer screening practices among Hispanic and non-Hispanic women residing near the United States-Mexico border, 1999-2000. Fam Community Health 26(2): 130-139.

10. Steven D, Fitch M, Dhaliwal H, Kirk-Gardner R, Sevean P, et al. (2004) Knowledge, attitudes, beliefs, and practices regarding breast and cervical cancer screening in selected ethno-cultural groups in northwestern Ontario. Oncol Nurs Forum 31(2): 305-311.

Your next submission with Juniper Publishers will reach you the below assets

- Quality Editorial service

- Swift Peer Review

- Reprints availability

- E-prints Service

- Manuscript Podcast for convenient understanding

- Global attainment for your research

- Manuscript accessibility in different formats ( Pdf, E-pub, Full Text, Audio)

- Unceasing customer service

Track the below URL for one-step submission https://juniperpublishers.com/online-submission.php 